\title{
Contrast-Induced Encephalopathy after Coil Embolization: A Case Report and Review of Literature
}

\author{
Yuwhan Chung ${ }^{1}$, Jiwook Ryu', Eui Jong $\mathrm{Kim}^{2}$ \\ Departments of ${ }^{1}$ Neurosurgery, ${ }^{2}$ Radiology, KyungHee University College of Medicine, Seoul, Republic of Korea
}

Corresponding author:

\section{Jiwook Ryu, MD}

Department of Neurosurgery, KyungHee University Hospital, 23 Kyungheedae-ro, Dongdaemun-gu, Seoul 130-702, Republic of Korea Tel: $+82-2-958-8385$

Fax: $+82-2-958-8380$

E-mail: drjoshuaryu@gmail.com

Received: December 18, 2020 Revised: February 04, 2021 Accepted: March 02, 2021

\begin{abstract}
Contrast-induced encephalopathy (CIE) is a rare and unexpected complication after coil embolization for the treatment of cerebral aneurysm. A 66-year-old woman underwent secondary coil embolization with iodixanol for recanalization of the left middle cerebral artery aneurysm. Preoperative computed tomography revealed encephalomalacia in the left frontal and temporal lobe caused by previous aneurysmal rupture. Two hours after the procedure, the patient showed status epilepticus and right hemiplegia. Fluid-attenuated inversion recovery imaging revealed extensive involvement of CIE in the left hemisphere. CIE-related symptoms gradually resolved with conservative treatment including antiepileptic drugs, mannitol, and methylprednisolone. Two-month follow-up magnetic resonance imaging revealed that the edema markedly improved in the parietal area but remained in the frontal area, and the patient completely recovered without any sequelae. Even iodixanol, which is an iso-osmo lar contrast medium, could lead to CIE manifesting as a serious condition such as status epilepticus. Endovascular neurosurgeons should always be aware of $\mathrm{CIE}$, especially when encephalomalacia is present.
\end{abstract}

Key Words: Contrast-induced encephalopathy, Encephalomalacia, Status epilepticus

\section{INTRODUCTION}

Contrast-induced encephalopathy (CIE) is an unexpected neurological complication after endovascular procedures with contrast media ${ }^{2,3,10}$. This complication has a rare incidence that broadly ranges from $0.3 \%$ to $1 \%$ but might increase to $4 \%$ when a hyperosmolar contrast is used ${ }^{1}$. Its clinical presentations are mainly cha racterized by transient cortical blindness, headache, memory loss, hemiparesis, aphasia, loss of coordination, confusion, seizures, and coma $^{13}$. A convincing theory of $\mathrm{CIE}$ is that hyperosmolar contrast agents remove fluid from the endothelial cells, causing them to disrupt the tight junctions of blood-brain barrier ${ }^{15}$.

lodixanol, which is the only iso-osmolar contrast medium, has a more favorable neurotoxicity profile than that of monomeric, nonionic contrast media ${ }^{1,14}$. The association between $\mathrm{CIE}$ and iodixanol contrast agents has rarely been reported ${ }^{3,10}$. Here, we report $\mathrm{CIE}$ where despite the use of iodixanol, the patient developed serious complications such as status epilepticus and hemiplegia after secondary coiling. The potential predisposing risk factors are also discussed.

\section{CASE REPORT}

A 66-year-old woman was admitted for the treatment of recanalization of a left middle cerebral artery (MCA) aneurysm. Ten years earlier, she underwent surgical clipping of an incidentally discovered
MCA unruptured aneurysm. However, one year earlier, she presented with subarachnoid hemornhage following the rupture of the previously clipped MCA aneurysm (Figure 1A) and underwent stent-assisted coiling at another hospital. The procedure was performed using 150 $\mathrm{ml}$ of iopromide (Ultravist ${ }^{\circledR}$, Bayer, N, United States) without adverse reaction to the contrast medium used.

Follow-up brain computed tomography (CT) revealed encephalomalacic change in the left frontal and temporal lobe caused by aneurysmal rupture (Figure 1B and 1C). Cerebral angiography was performed using $100 \mathrm{ml}$ of iodixanol Nisipaque 270, GE Healthcare, Princeton, NJ, USA) without any complications and revealed the major recanalization of previously coiled aneurysm (Figure 1D and $1 \mathrm{E})$. The coil embolization procedure was performed via the right transfemoral approach. A guidewire was inserted into the left intemal carotid artery (ICA) and extended to the tortuous carotid artery. Subsequently, 6-Fr guiding catheters (Asahi Fubuki ${ }^{\circledR}$; Asahi Intecc Co., Ltd., Aichi, Japan) were placed in the left ICA, and a microcatheter (SL 10, Stryker Neurovascular, CA, USA) and microwire (Troxcess, Microvention, CA, USA) were placed in the aneurysm sac through the strut of the previous stent (trans-cell technique). The aneurysm was completely obliterated with six coils (Axium Prime, Medtronic, Minnesota, USA), maintaining the distal MCA arterial flow. A total of $250 \mathrm{ml}$ of iodixanol was used during the procedure. There was no thromboembolic event during the procedure. She recovered from anesthesia without any complications. However, the patient's postoperative brain CT revealed contrast enhancement and gyral effacement, indicating cerebral edema in the left hemisphere (Figure 2A). 
Two hours after the procedure, the patient developed sudden-onset right-sided hemiplegia and aphasia. She gradually became more lethargic and finally developed generalized tonic-clonic seizures for $5 \mathrm{~min}$. Although intravenous lorazepam (4 mg) was administered repeatedly, the seizures did not stop and even prolonged for more than 30 min. She was administered $1000-\mathrm{mg}$ phenytoin sodium
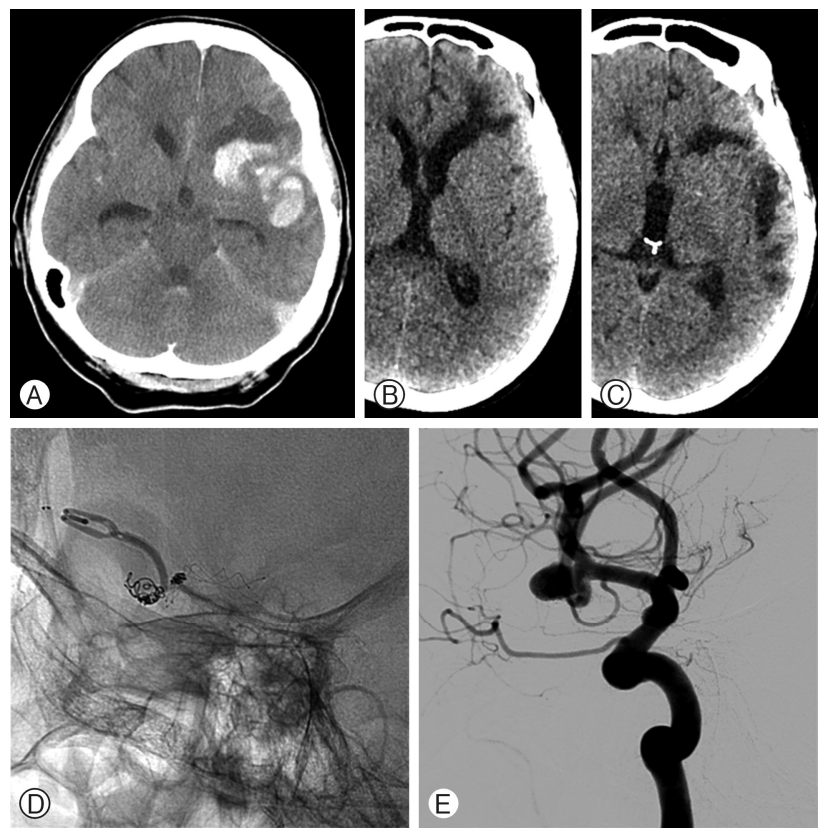

Figure 1. Clinical history before secondary coil embolization. (A): One year earlier, the patient had subarachnoid hemorrhage due to the rupture of the left middle cerebral artery aneurysm, which had previously undergone surgical clipping 10 years earlier. (B) and (C): Recent follow-up computed tomography before secondary coiling revealed encephalomalacia in the left frontotemporal area. (D) and (E): Recent cerebral angiography revealed major recanalization of the previously occluded aneurysm by surgical clipping and stent-assisted coiling. followed by 1000-mg sodium valproate with no respite in seizures. She was considered to be experiencing refractory status epilepticus and moved to the intensive care unit for therapeutic coma induction. Seizure control was achieved at a dose of $2 \mathrm{mg} / \mathrm{kg} / \mathrm{h}$ of propofol. Under high suspicion of postoperative stroke, a follow-up cerebral angiogram and diffusion-weighted imaging were performed, but
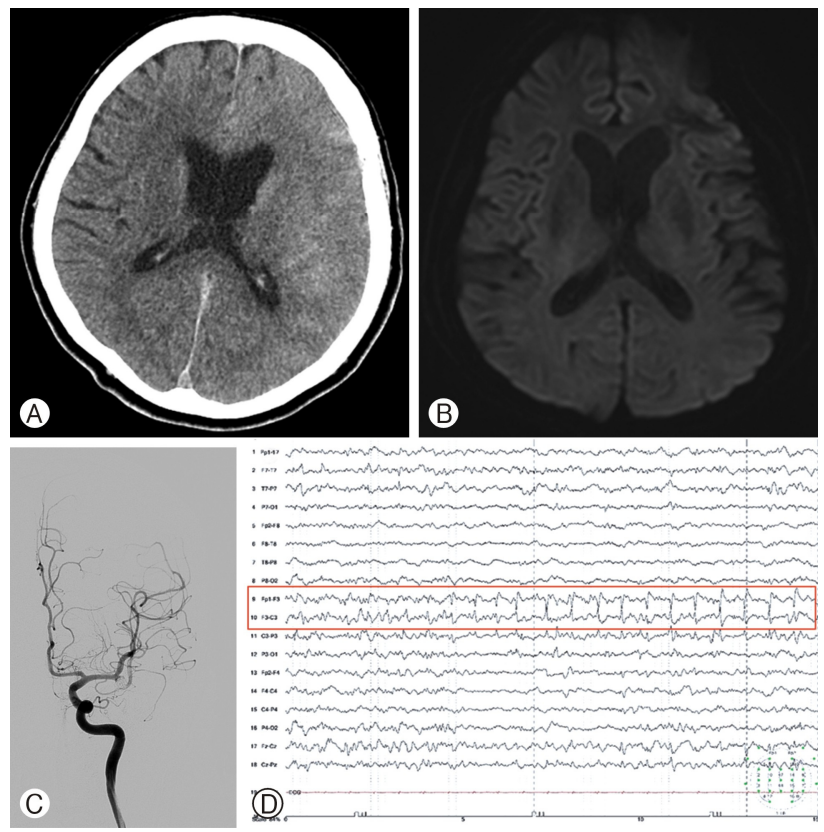

Figure 2. Postoperative findings. (A): Immediate postoperative computed tomography demonstrated contrast enhancement and gyral effacement extensively in the left hemisphere. (B): Postictal diffusionweighted imaging revealed no evidence of acute infarction. (C): Followup of the left carotid angiogram $3 \mathrm{~h}$ after secondary coiling confirmed the patent flow of the left middle artery and complete obliteration of the aneurysm (D): Ictal electroencephalography revealed repetitive sharp waves concentrated in the left fronto-centro-parietal area (red box).

Table 1. Reported cases of contrast-induced encephalopathy after coil embolization

\begin{tabular}{|c|c|c|c|c|c|c|c|c|c|c|c|c|}
\hline $\begin{array}{l}\text { Author and } \\
\text { year }\end{array}$ & $\begin{array}{c}\text { Case } \\
\text { no. }\end{array}$ & $\begin{array}{l}\text { Sex/ } \\
\text { age }\end{array}$ & \begin{tabular}{|l|} 
SAH/ \\
URA
\end{tabular} & $\begin{array}{l}\text { Aneurysm } \\
\text { site }\end{array}$ & Onset time & Symptoms & $\begin{array}{l}\text { Volume of } \\
\text { contrast }(\mathrm{ml})\end{array}$ & $\begin{array}{l}\text { Contrast } \\
\text { agent }\end{array}$ & $\begin{array}{l}\text { Side of guiding } \\
\text { catheter }\end{array}$ & Extent of ClE & \begin{tabular}{|l} 
T2 high SI \\
lesion
\end{tabular} & $\begin{array}{l}\text { Clinical } \\
\text { resolution }\end{array}$ \\
\hline $\begin{array}{l}\text { Uchiyama et } \\
\text { al. } 2003^{10}\end{array}$ & 1 & M/72 & SAH & Acom & 1 hour & $\begin{array}{l}\text { Hemiparesis, } \\
\text { motor aphasia }\end{array}$ & 260 & lopamidol & Left ICA & $\begin{array}{l}\text { Left cerebral } \\
\text { hemisphere }\end{array}$ & NA & 1 week \\
\hline $\begin{array}{l}\text { Leong et al. } \\
2012^{16}\end{array}$ & 2 & $\mathrm{~F} / 50$ & URA & ICA & Immediate & $\begin{array}{l}\text { hemiparesis and } \\
\text { sensory loss, right- } \\
\text { sided neglect }\end{array}$ & 220 & lopromide & NA & $\begin{array}{l}\text { Left cerebral } \\
\text { hemisphere }\end{array}$ & Present & 1 year \\
\hline $\begin{array}{l}\text { Nagamine et } \\
\text { al. } 2014^{24}\end{array}$ & 3 & $F / 58$ & URA & ICA & 4 weeks & $\begin{array}{l}\text { Hemiparesis, } \\
\text { agraphia }\end{array}$ & 316 & lohexol & Left ICA & \begin{tabular}{|l} 
Leff fronto- \\
parieto-occipital
\end{tabular} & Present & 50 days \\
\hline \multirow[t]{2}{*}{$\begin{array}{l}\text { Matsubara et } \\
\text { al. } 2017^{13}\end{array}$} & 4 & $F / 63$ & URA & Acom & Immediate & Hemiparesis & 210 & lodixanol & Left ICA & $\begin{array}{l}\text { Bilateral } \\
\text { frontal }\end{array}$ & NA & 1 month \\
\hline & 5 & $F / 51$ & URA & ICA & Several hours & $\begin{array}{l}\text { Visual } \\
\text { distrurbance }\end{array}$ & 270 & lopamidol & Left VA & $\begin{array}{l}\text { Bilateral } \\
\text { occipital }\end{array}$ & NA & 1 week \\
\hline $\begin{array}{l}\text { Onishi et al. } \\
2018^{4}\end{array}$ & 6 & $F / 67$ & URA & $\begin{array}{l}\text { IC-PC and } \\
\text { AChA }\end{array}$ & $\begin{array}{l}\text { Intra-operative, } \\
30 \text { min }\end{array}$ & $\begin{array}{l}\text { Hemiparesis, } \\
\text { aphasia }\end{array}$ & NA & NA & Left ICA & $\begin{array}{l}\text { Left cerebral } \\
\text { hemisphre }\end{array}$ & NA & 1 day \\
\hline Our case & 7 & $F / 66$ & $\mathrm{SAH}$ & $\begin{array}{l}\text { MCA } \\
\text { bifurcation }\end{array}$ & 2 hours & $\begin{array}{l}\text { Status epilepticus, } \\
\text { hemiplegia }\end{array}$ & 250 & lohexanol & Left ICA & $\begin{array}{l}\text { Left fronto- } \\
\text { temporal }\end{array}$ & Present & 2 months \\
\hline
\end{tabular}

${ }^{*} \mathrm{AChA}$, anterior choroidal artery; Acom, anterior communicating artery; CIE, contrast-induced encephalopathy; ICA, internal carotid artery; IC-PC, internal carotid-posterior communicating artery; SAH, subarachnoid hemorrhage; SI, signal intensity; URA, unruptured aneurysm; VA, vertebral artery 
they revealed patent MCA flow without cerebral infarction (Figure $2 \mathrm{~B}$ and $2 \mathrm{C}$ ). Electroencephalography demonstrated repetitive sharp waves concentrated in the left frontocentroparietal area (Figure 2D). Hydration and intravenous administration of methylprednisolone, mannitol, and anticonvulsant agent were also provided for symptom control. Propofol tapering was attempted after 72 hours of seizurefree period.

Recovery (with spontaneous eye opening) started to occur on postoperative day 7, and the hemiplegia gradually resolved. T2-weighted images demonstrated extensive cerebral edema of the left frontotemporo-parietal area (Figure 3A and 3B). Two-month follow-up magnetic resonance imaging (MR) revealed that the edema markedly improved in the parietal area but remained in the frontal area (Figure 3C and 3D). Finally, the patient completely recovered without any neurologic sequelae.

\section{DISCUSSION}

Since 2010, there has been an increasing trend on the incidence of $\mathrm{ClE}$ (Table 1). To the best of our knowledge, there has been only one case that reports $\mathrm{CIE}$ after coil embolization using iodixanol
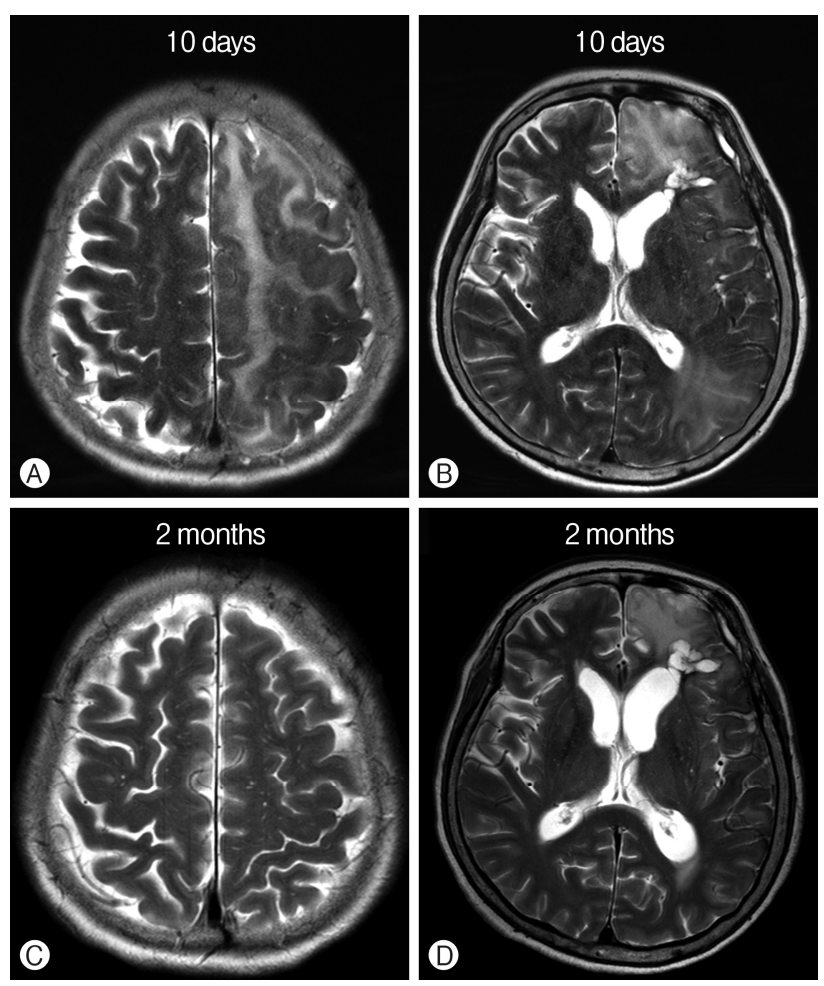

Figure 3. Serial postoperative magnetic resonance images. (A) and (B): One-week postoperative T2-weighted images demonstrated extensive involvement of contrast-induced encephalopathy in the left hemisphere. (C) and (D): Two-month postoperative T2-weighted images showed that high signal lesion in the parietal area was no longer observed, but that in the frontal area adjacent to the encephalomalacic lesion remained. contrast medium?.

The clinical presentation of $\mathrm{CIE}$ can sometimes mimic acute stroke, but imaging findings present several characteristics of CIE. The most common symptoms of CEE include cortical blindness, headache, vomiting, agitation, hemiplegia, seizures, confusion, transient global amnesia, and dysarthria-aphasia, ${ }^{4,15}$. Cerebral angiography and diffuse-weighted imaging were also performed because of high clinical suspicion for postoperative acute ischemic stroke. Radiologic findings of $\mathrm{ClE}$ are characterized, consistent with our case, by gyral swelling and hyperintensity on T2 image on MRI and also abnormal cortical contrast enhancement, edema, and subarachnoid contrast enhancement on $\mathrm{CT}^{8}$. Thus, it is important to differentiate between $\mathrm{CIE}$ and stroke as promptly and accurately as possible.

Possible risk factors for $\mathrm{ClE}$ include chronic hypertension (HTN) with impaired cerebral autoregulation, chronic kidney disease, and a large volume of contrast media, ${ }^{9,15}$. This patient had a history of chronic HTN, previous SAH, and the large amount of contrast (250 $\mathrm{ml}$ ) administration for repeat arteriograms. Additionally, given the evidence of long-standing persistent T2 high signal of the left frontal lobe in the late stage of $\mathrm{CIE}$, the presence of precedent encephalomalacia may have predisposed the patients to $\mathrm{CIE}$ and facilitated the contrast agent to disnupt the blood-brain barrier, causing cerebral edema ${ }^{5}$.

It is unclear whether the difference in types and doses of the contrast media develops CIE. Theoretically, iodixanol, which is an isoosmolar contrast agent, hardly induces blood-brain barrier damage, and it has been associated with fewer adverse effects and only rarely with $\mathrm{ClE}^{7,10}$. A comparison study showed both iodixanol and iopromide to be safe, effective, and well tolerated ${ }^{12}$. CIE also developed during angiography procedure with contrast volumes less than $40 \mathrm{~mL}$ and even with $25 \mathrm{ml}$ of contrast media for local injection into the carotid artery, ${ }^{6,11}$. In our case, CIE did not develop during cerebral angiography with $100 \mathrm{ml}$ of iodixanol but during coil embolization with $250 \mathrm{ml}$ of iodixanol. Thus, iodixanol-induced encephalopathy appears to be an idiosyncratic reaction.

There is no definite treatment strategy of $\mathrm{CIE}$ given the unexpected and rare nature of the complication ${ }^{8}$. Previous reports demonstrated that hydration and intravenous steroid and mannitol administration may be helpful for symptom control ${ }^{7,10}$. Although the prognosis of $\mathrm{CIE}$ has been benign with a wait-and-see approach in most reported $\operatorname{cases}^{10}, \mathrm{ClE}$ could present with severe neurological symptoms, and permanent neurological symptoms may remain ${ }^{8}$.

\section{CONCLUSION}

Despite the use of iodixanol contrast media, CIE can develop during coil embolization. Endovascular neurosurgeons should always be aware of $\mathrm{ClE}$, especially when encephalomalacia is present.

\section{Informed Consent:}

Informed consent was obtained from all individual participants included in the study. 


\section{REFERENCES}

1. Aulie Michelet A: Effects of intravascular contrast media on blood-brain barrier. Comparison between iothalamate, iohexol, iopentol and iodixanol. Acta Radiol 28:329-333, 1987

2. Bettmann MA: Angiographic contrast agents: conventional and new media compared. AJR Am J Roentgenol 139:787-794, 1982

3. Chisci E, Setacci F, de Donato G, Setacci C: A case of contrastinduced encephalopathy using iodixanol. J Endovasc Ther 18: 540-544, 2011

4. Dangas G, Monsein LH, Laureno R, Peterson MA, Laird JR, Jr., Satler LF, et al.: Transient contrast encephalopathy after carotid artery stenting. J Endovasc Ther 8:111-113, 2001

5. Junck L, Marshall WH: Neurotoxicity of radiological contrast agents. Ann Neurol 13:469-484, 1983

6. Lantos G: Cortical blindness due to osmotic disruption of the blood-brain barrier by angiographic contrast material: CT and MRI studies. Neurology 39:567-571, 1989

7. Law S, Panichpisal K, Demede M, John S, Marmur JD, Nath J, et al.: Contrast-induced neurotoxicity following cardiac catheterization. Case Reports in Medicine 2012, 2012

8. Leong S, Fanning N: Persistent neurological deficit from iodinated contrast encephalopathy following intracranial aneurysm coiling: A case report and review of the literature. Interven- tional Neuroradiology 18:33-41, 2012

9. Matsubara N, Izumi T, Miyachi S, Ota K, Wakabayashi T: Contrast-induced Encephalopathy Following Embolization of Intracranial Aneurysms in Hemodialysis Patients. Neurol Med Chir (Tokyo) 57:641-648, 2017

10. Park JC, Ahn JH, Chang IB, Oh JK, Kim JH, Song JH: A Case of Unusual Presentation of Contrast-induced Encephalopathy after Cerebral Angiography Using Iodixanol. J Cerebrovasc Endovasc Neurosurg 19:184-188, 2017

11. Potsi S, Chourmouzi D, Moumtzouoglou A, Nikiforaki A, Gkouvas K, Drevelegas A: Transient contrast encephalopathy after carotid angiography mimicking diffuse subarachnoid haemorrhage. Neurol Sci 33:445-448, 2012

12. Pugh N, Sissons G, Ruttley M, Berg K, Nossen J, Eide H: Iodixanol in femoral arteriography (phase III): A comparative double-blind parallel trial between iodixanol and iopromide. Clinical Radiology 47:96-99, 1993

13. Studdard WE, Davis DO, Young SW: Cortical blindness after cerebral angiography. Case report. J Neurosurg 54:240-244, 1981

14. Wilson AJ, Evill CA, Sage MR: Effects of nonionic contrast media on the blood-brain barrier. Osmolality versus chemotoxicity. Invest Radiol 26:1091-1094, 1991

15. Yu J, George Dangas M: New insights into the risk factors of contrast-induced encephalopathy. Journal of Endovascular Therapy $18: 545,2011$ 